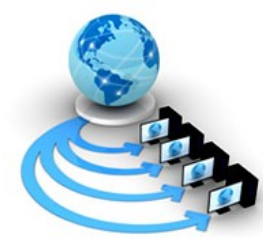

Volume 9, No. 5, September-October 2018

\title{
LITTLE THINGS THAT MATTERS - GREEN INFORMATION TECHNOLOGY TODAY - A REVIEW
}

\author{
Malasowe Bridget O. (PhD) \\ Lecturer Computer Science Dept., \\ College of Education,Agbor, Delta State, Nigeria
}

\author{
Emuobonuvie Andy \\ Lecturer Computer Science Dept., \\ College of Education,Agbor, Delta State, Nigeria
}

\begin{abstract}
Information Technology has been a very important tool in homes and organisations today. It has really enhanced human activities greatly. Despite its enomous benefit, it has posed some level of serious risk to the society. While public awareness of environmental sustainability is growing, there is concern about the economic costs of shifting to a greener economy and better undertsanding of Green Information Technology. In other to satisfy IT users demand, production of IT equipment has increased. Its computing resources consume high energy that have resulted to carbon footprints $\left(\mathrm{CO}_{2}\right.$ emissions). Green IT plays an important role in addressing these issues by offering various Green IT and IS initiatives and models through which efficiencies are met to reduce the emissions. Green IS is the usage of information systems to achieve environmental objectives, while Green IT emphasizes reducing the negative environmental impacts of IT production, usage and disposal. This paper reviews the extent of existing research work done on Green IS and IT, its level of awareness and its implementation. With the increased rate of IT usage in recent time and the high negative effect caused by IT sector, its a great concern for all hands to be on deck to go green in other to holisticly reduce the carbon footprint. The level of awareness and basic understanding of green IT and IS is a key for better adoption and implementation of Green Technology.
\end{abstract}

Keywords: Carbon Productivity, Green Information Technology (GIT), Environmental Sustainability, Green Information System (GIS), Data Centre, $\mathrm{CO}_{2}$ Emission

\section{INTRODUCTION AND BACKGROUND}

There is an appreciable increase in the interest in the environmental impacts of Information Technology (IT). This is as a result of the increased response to public concern/consciousness about the environment and growing eco-consciousness in organisations. Scientific research and widespread media reporting on global warming and other environmental threats has made this possible. Sustainability has started to become a significant issue in the narrow sense of reducing the direct negative environmental impacts of IT use to the ecosystem. Furthermore, energy efficiency in hardware and data centres, recycling of electronic waste, environmentally friendly designs, emphasizing reusability and elimination of toxic chemicals, has continued to receive great attentions with the aim of possible reduction of emissions and lower energy costs. But organisations fail to endorse their Green IT initiatives due to lack of innovativeness in their approaches and for failing to gather impetus from the respected stakeholders [40]. According to reference [40], considering the tough economic challenges organisations are currently facing as a result of the global financial crisis, Green IT may not be perceived to be a critical organizational priority. Also, management practices promoting the adherence to Green IT are inactive as well. Organisations who have fully implemented Green IT in one way or the other, face barriers such as lack or inadequate funding, inadequate skills to implement and manage the initiatives, not clear aims as well as inadequate knowledge of the system to support the technical necessities [3]. It is widely recognised throughout literature and practice that hardware has an enormous negative impact on the environment. The unlawful disposing of hardware may lead to serious health issues [37]. Also, energy consumption by IT services (institutions, organisation, data centres) directly or indirectly contributes to carbon dioxide $\left(\mathrm{CO}_{2}\right)$ emissions to the ecosystem. Moreover the extreme use of IT in our everyday life has become the cause of several environmental issues including $\left(\mathrm{CO}_{2}\right)$ emissions [42] and potential global warming [43]. Therefore, both IT hardware manufacturers and the organizations using IT need to apply environmental sustainability policies containing product recycling, pollution prevention and sustainable development in managing IT [28]. Green IT refers to the introduction of innovative IT products, application, services and practices that will reduce the impact of IT on the environment [30]. Green Information Technology (IT) is defined as a "systematic application of ecological-sustainability criteria, such as pollution prevention, product stewardship and use of clean technologies, for the creation, sourcing, usage and disposal of IT technical infrastructure, as well as within the human and managerial components of the IT infrastructure [28].

The primary goal behind Green IT strategy is to reduce the energy consumption, maintain the operating costs and at the same time manage the constantly increasing requirements for performance and capacity of resources. The effect of using IT in the environment is categorized into two, these are first order effect which is due to the negative environmental impact of IT production, use and disposal and second order effect [10]; [13]. The second order involves the positive impact of using Information Systems (IS) to improve the eco-sustainability of businesses and society; this is termed Green IS [21]; [44]. Reference [30], consolidated the concept of Green IT. The author proposed four domains of Green IT which are Green use, Green design, Green manufacturing and Green disposal of IT Systems (figure 1). It can be seen in reference [30] concept that to implent Green IT and record a good success with 
respect to environmental sustanability it has to be a holistic approach for all stake holders involvment.

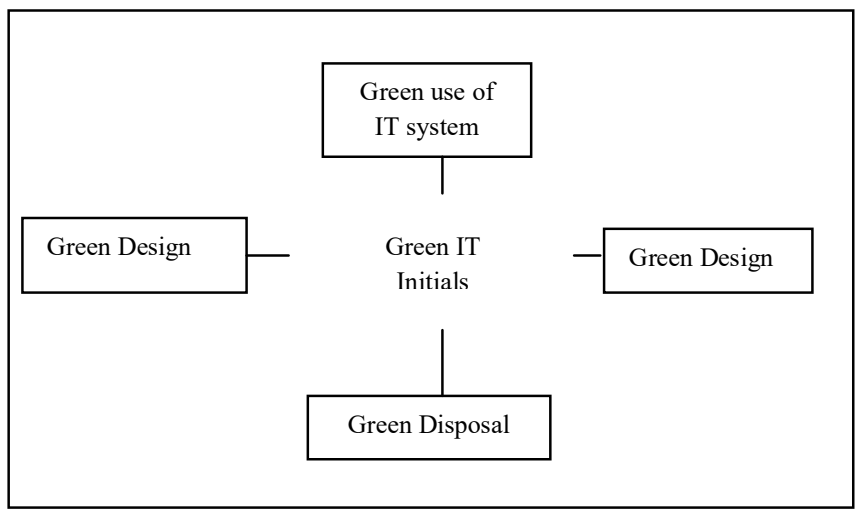

Figure 1: Green Information Technology Domains [30]

\section{Research Objectives:}

This paper seeks to review the extent of existing research in Green Information Technology today and identify the gap in its adoption. Also, it highlights the extent to which IT professionals' value environmental sustainability, taking action to be part of the solution to the global challenge of climate change, and reacting to Green IT.

\section{LITERATURE REVIEW}

\subsection{Concept of Green Technology: The Beginning}

The importance of Green Technology was made evident when computing attained critical mass in the early 1990s. The late 1990s and early 2000s witnessed many regulatory milestones and companies responded with innovations to incorporate green technology in subquent years [22]. Green Technology is the application of environmental science to offer economically viable solutions that preserve the natural environment and resources, while also curbing the negative impacts of human involvement in the use of the IT equipments. This motivated the search for ways to apply green technology in computing to alleviate the serious environmental and health concerns [22]. Some examples of the application of green technology in computing include [22]:

- reducing the use of environmentally hazardous materials like lead and others in IT material prodcution

- promoting the use of recyclable materials and minimizing use of non-biodegradable components.

- promoting practices such as energy cost accounting, virtualization, eWaste recycling etc.

\subsection{The Initial Thoughts of Green IT Model}

Reference [8] gave five key components of Green IT as shown in figure. 2

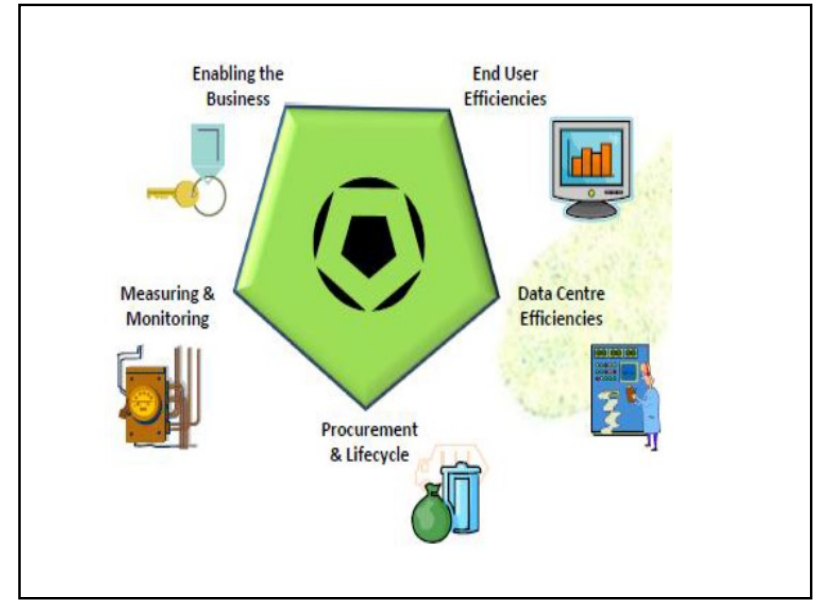

Figure 2: Five Key Components of Green IT [8]

Fortunately, there are many simple steps that can be taken to do this no matter the size of an organisation is business, or process(es). Many IT vendors have major initiatives underway to green their products, services and practices. This includes building computers with more environmentally friendly materials, designing them to consume less energy, providing recycling programs to dispose of old systems, developing virtualization and cloud computing alternatives, and providing tips to businesses that want to go green.

\subsection{Reason why we should be concerned about Green \\ IT}

Green IT as defined by [50], is the study and practice of using computers and IT resources in a more efficient and environmentally responsible way. Computers and computing eats up a lot of natural resources, from the raw materials needed to manufacture them, the power used to run them, and the problems of disposing them at end of life [50]. According to refrence [50], all businesses as well as all human activities are increasingly dependent on IT. Hence, the current climate change today is detoriating by the minute and every part of the world is experiencing its impact. There is therefore an urgent need for every individuals to be concerned and embrace Green IT because its the only solution to tackle the negative effect caused by the IT sector.

\subsection{Reviewed Literatures}

There are many published literatures on Green Information Technology (GIT) and Green Information System (GIS) and its driving factors. Despite the wealth of research going on in this area, no appreciable implementation has been recorded as well as positive change in the global warming issues. Either the level of awareness is low or lack of full understanding, financing or implementation is the major problem in this issue. References [2]; [5]; [49] had the perspective that Information Technology plays significant roles in creating and determining sustainability issues such as Green Information Technology (GIT) in our society. Each IT lifecycle stage starts from manufacturing to implementation and disposal with respect to environmental issues [30]. In 2007, 1.3\% of global greenhouse gas emissions were produced by the IT with this sector consuming $3.9 \%$ of the 
world's electricity [23]. Also, refeerence [1]; and [5] perspectives is that, IT produced an unwanted effect of increasing the environmental pollution generated by business activities and human activities. Also, in recent time, IT lifespan is decreasing and the waste of energy on electronics is increasing very fast [10]. Hence, there is an urgent need for IT hardware producers, manufacturers and users as well to practice environmental sustainability (Green IT) including sustainable development, product stewardship as well as pollution prevention [21].

In many organizations, most energy is consumed by IT. Hence, decreasing the amount of carbon released into the atmosphere and saving costs are both the results of greening IT [6]; [24]; [32]. For instance, ICTs utilization in businesses in a country like Australia played a role in releasing more than $1.5 \%$ of all the $\mathrm{CO}_{2}$ released in the country. This amount is higher than what is released by the cement and civil aviation industries [26]. It means that the environmental footprint of business organizations can be decreased through green IT. Reference [33] estimated that an organization's data center consumes the most energy in terms of cost. Hence, the total environment value of ownership can be increase and the total cost of technology ownership can be reduced by Greening IT. Moreover, it is hoped that Greening IT can have a major influence in enhancing business sustainability creativity [48].

Reference [26], researched on - The extend of green IT adoption and its driving and inhibiting factors. His aim was to diffuse the innovation theory in organization. Reference [28] had an empirical study on Green IT adoption: his emphasis was on a motivating organization on the need to adopt Green IT. Reference [34] worked on a resource based framework of Green IT capability toward firms, their emphasis was on competitive advantage of adoption of Green IT. Reference [4] addressed Green IT based on an institutional perspective on the adoption of Green IT and IS. Their approach was explanatory. Reference [44] approach was on Senior managers' perception on green Information Systems (IS) adoption and environmental with respect to performance. Their result was based on a field survey. Reference [51], examined the behavior of ecotechnological knowledge of Smart Green IT adoption. Their work was on a self determined perspective. Reference [14] research was on agenda on managerial intention to green IT adoption. Their approach was on Norm Activation perspective, applying Norm Activation Theory. Reference [31] measured the carbon footprint of a higher institution in Nigeria and presented a generic model for campuses to adopt. Moreover, there are very limited empirical studies in the GIT area [3]; [11]; [20]. Majority of the earlier GIT researcher focussed more on defining a research agenda $[7 ; 12 ; 17]$ and explaining, both theoretically and empirically, the drivers and consequences of adoption of Green IT in organizations [12]; [3]; [4]. However, despite the importance of organizational decision maker's role in adopting information technology, there is a lack of research investigating the formation of decision makers intention for the adoption of Green IT since "organizations do not make decisions, individuals in the organisations do [15]; [39].

One of the areas of IT businesses where environmental sustainability is becoming imperative is data centers. They are found major culprits in consuming huge energy in their overall operations [19]. In very recent time data centers have become one of the largest energy consumers, accounting for approximately $2 \%$ of total global energy use [45]. As the demand for data centers continues to increase by the minutes, these powerhouses are faced with heavy power, cooling, performance as well space constraints which is associate with environmental, technological, and economical sustainability issues [19]. Data centers do not only consume huge energy but also major contributors towards company's energy bill [18]. Reference [9] warns that, if data centers managers remain unaware of energy problems, they will most probably run the risk of doubling their energy costs between 2005 and 2011 [9]. If energy costs continue to double every 5 years, they will be substantially increase to $1,600 \%$ between 2005 and 2025 [46]. According to IDC, the cost to power the servers will exceed the cost of servers in the nearest futire. An EPA report presented to U.S congress in 2007 emphasized that, current energy consumption in data centers is leading to an annual increase in the emission of $\mathrm{CO}_{2}$ (green house gases) from 42.8 million metric tons (MMTCO2) in 2007 to $67.9 \mathrm{MMTCO} 2$ in 2011 (EPA, 2007). Emissions of GHG from aviations, transportations, shipping, in homes, telecommunications and manufacturing industries are rising very fast, but the emissions from IT are mounting faster. Reductions achieved through the use of Green IT in key economic sectors would be five times greater than the growth in emissions from the IT sector itself [19]. Continuous increase in these emissions from IT is projected to increase from $3 \%$ of total global emissions in 2009 to a whopping 6\% by 2020 [36] (Table 1).

Table 1. CO2 emmissions (carbon foot print) climate group and the global sustainability initiative. [36]

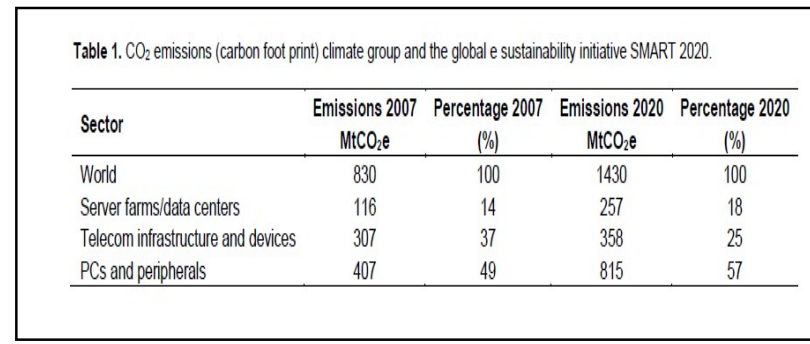

\subsection{Current Energy Feature}

In recent time Information and Communication Technology (ICT) emissions are increasing at an appreciating growth rate of $6 \%$ per year; with this growth rate ICT could represent $12 \%$ of worldwide emissions by 2020 [36]. Based on current high IT demands, organisations needed to achieve business set goals, data centres also anticipate growth as a result of this demand, high energy consumption is needed to satisfy high society demand. The high energy consumption in data centres can be managed efficiently and accurately by adopting Green Energy monitoring metrics like Power Usage Efficiency (PUE) to measure individual components for performance and efficiency [52]. Before now, data centers resource were highly optimized to provide high performance for business operation until Green IT energy monitoring metrics was introduced. Technologies like virtualization, cloud computing and building data centers using the abundance renewable energy sources (water, solar among others) have emerged as well due to energy efficiency requirements [52]. Carbon Trust, reported that office equipments consumes 15 
$\%$ of the total electricity used in office and it's likely to increase to $30 \%$ by 2030 [BCS, 2012]. Moreover, reducing energy consumption requires Planning and Operational improvements [52]. The possible planning improvements requirements are:

- The design of Infrastructure should include solution like virtualization, cloud computing and building data centers at available abundance renewable energy sources.

- Strategic energy efficient techniques that are used in data center should be aligned with its Green IT policy, which allows energy to be monitored and managed at components level.

- Allows data centres to cope up with continous growing business demands.

- Analyze system performance requirements as per the business needs and its energy consumption requirements.

Operational improvements requirements are:

- Power Usage Efficiency (PUE), which only indicates ratio of infrastructure to IT power consumption

- An elementary framework and techniques to measure power consumption and efficiency is still in evolution stage in market as at 2014.

- There is no industry standard metrics to calculate energy and carbon footprints as at 2014.

- Server consolidation through which underutilized server resources can be consolidated for energy efficiency which saves energy and cost and at the same time reduces the emission of greenhouse gases.

\subsection{Organizational and Individual factors for Green IT implementation and Innovation Process}

It is a very strong fact that business organizations and individuals play a very critical role in reducing climate change and upholding environmental sustainability by applying their dominance attitude in the global economy [17]. According to reference [17], organizations should pursue environmental sustainability by informing stakeholders of the need to make changes to business as usual, by motivating them to take actions to achieve environmental objectives and by assessing the impact of such actions on economic and environmental performance. Also, reference [38] opined that environmental sustainability practices can lead to changes in organizational processes. Due to the rapid growth in natural resource consumption coupled with the increase of greenhouse gas emissions, sustainability has become a crucial concept for corporate management [47] for organizations and also individuals. Top management team in organizations look for opportunities which are more innovative and sustainable [38]. The successful implementation of Green IT initiatives depends on several factors [3]. The head of management and IT managers should be aware of the factors influencing Green IT for successful implementation [35].

\section{PROJECTING AHEAD}

Green IT is only going to grow bigger because of its clear advantage. As global warming is becoming more important to tackle, all (both individuals and oranisations) will need to focus on proper Green IT understanding and adoption. It begins with a proper understanding of GIT to know which best method to adopt and to sustain it. It has become everyone responsibility to push green philosophy for the sake of our environment.

It has also become a moral responsibility not only for companies but also for end users and clients. It will soon get to the point that unless organizations go green, people might hesitate to conduct business with such organization. In the near future, we can see a growing awareness about environment-friendly behaviors and people are likely to prefer the use of products and services from companies that stand up to their green ideals.

\section{DISCUSSIONS AND CONCLUSION}

Ensuring a secure energy supply, preserving the environment and protecting the climate are central challenges seriously facing today's world. Environmentally friendly technologies are the key to sustainable economic activity. Based on the reviewed literature, it can be strongly accepted that the level of awareness of GIT is still very low especially in developing companies. Individuals in their homes has alot to contribute in the issue of IT contribution to global warming. Because the level of IT use in homes is increasing by the minutes as well as in organizations, if the energy consumptions are well monitored and managed at component level. It will go a long way to reduce the level of $\mathrm{CO}_{2}$ emission both from home and organisations. In conclusion, going green in all aspect of the use of IT components through its life span is very important for all to be part of the solution to the global warming issue. Awareness level of Green IT is still very low in some part of the world, especially developing countries. It is therefore a call to all to go green in our emisssion activity of $\mathrm{CO}_{2}$ no matter how small. This holistic approoach will sure record a huge success in the fight for reduction of carbon emmision from the IT sector.

\section{REFERENCES}

[1] Berthon, P., and Donnellan, B. (2011). The Greening of IT: Paradox or promise? The Journal of Strategic Information Systems, 20(1), 3-5.

[2] Butler, T., and Daly, M. (2009). Environmental responsibility and green IT: An institutional perspective. In ECIS (pp. 1855-1866).

[3] Bose, R., and Luo, X. (2011). Integrative framework for assessing firms' potential to undertake Green IT initiatives via virtualization-A theoretical perspective. The Journal of Strategic Information Systems, 20(1), 38-54

[4] Chen, A. J., Watson, R. T., Boudreau, M. C., and Karahanna, E. (2011). An institutional perspective on the adoption of Green IS and IT. Australasian Journal of Information Systems, 17(1).

[5] Chen, A. J., Boudreau, M. C., and Watson, R. T.(2008). Information systems and ecological sustainability. Journal of Systems and InformationTechnology, 10(3), 186-201.

[6] Donston, D. (2007). Green IT generates fertile ideas. eWeek, 24(16), 46.

[7] Elliot, S. (2011). Transdisciplinary perspectives on environmental sustainability: a resource base and framework for IT-enabled business transformation. Mis quarterly, 35(1), 197-236.

[8] Graeme Philipson (2010). The Green IT FrameworkStructure and Metricsll. International Green IT Awareness Week.

[9] Gartner (2008). Sustainable IT, A Gartner Briefing, Gartner, Dublin. 
[10] Hilty, L. M. (2005). Electronic waste-an emerging risk? Environmental Impact Assessment Review, 25(5), 431-435. 21(1), 17-40.

[11] Jenkin, T. A., McShane, L., and Webster, J. 2011 a. Green information technologies and systems: Employees' perceptions of organizational practices. Business and Society, 50(2), 266-314.

[12] Jenkin, T. A., Webster, J., and McShane, L. 2011b. An agenda for 'Green'information technology and systems research. Information and Organization, 21(1), 17-40.

[13] Köhler, A., and Erdmann, L. 2004. Expected environmental impacts of pervasive computing. Human and Ecological Risk Assessment, 10(5), 831- 852.

[14] Lei, C. F., and Ngai, E. W. T. 2014. A research agenda on managerial intention to green it adoption: from norm activation perspective.

[15] Lei, C. F., and Ngai, E. W. T. (2013a). Green Information Technologies Adoption: A Managerial Perspective. In PACIS (p. 274).

[16] Lei, C. F., and Ngai, E. W. T. (2013). Green IT Adoption: An Academic Review of Literature. In PACIS (p. 95).

[17] Melville, N. P. 2010. Information systems innovation for environmental sustainability. MIS quarterly, 34(1), 1-21.

[18] McNamara W, Seimetz G, Vales KA (2008). Best Practices for Creating the Green Data Center.

[19] Mueen Uddin, Muhammad Talha2, Azizah Abdul Rahman1, Asadullah Shah3, Jameel Ahmed Khader4 and Jamshed Memon1 (2012). Green Information Technology (IT) framework for energy efficient data centers using virtualization. International Journal of Physical Sciences Vol. 7(13), pp. $2052-2065$.

[20] Mishra, D., Akman, I., and Mishra, A. 2014. Theory of reasoned action application for green information technology acceptance. Computers in human behavior, 36, 29-40.

[21] Molla, A., and Abareshi, A. (2012). Organizational green motivations for information technology: empirical study. The Journal of Computer Information Systems, 52(3), 92.

[22] Nayab N.( 2011) •\| Related Guides: Green Technology\| Kyoto Protocol.

[23] Malmodin, J., Moberg, Å., Lundén, D., Finnveden, G., and Lövehagen, N. (2010). Greenhouse gas emissions and operational electricity use in the ICT and entertainment and media sectors. Journal of Industrial Ecology, 14(5), 770-790.

[24] Mines, C. (2008). The dawn of green IT services. Cambridge, MA: Forrester Research.

[25] Molla, A. 2008. GITAM: A Model for the Adoption of Green IT. ACIS 2008 Proceedings, 64.

[26] Molla, A. (2009). Organizational motivations for Green IT: Exploring Green IT matrix and motivation models. PACIS Proceedings, page 13.

[27] Molla, A. 2009. The extent of Green IT adoption and its driving and inhibiting factors: An exploratory study. Journal of Information Science and Technology, 6(4), 1-21.

[28] Molla, A., and Abareshi, A. (2011). Green IT Adoption: A Motivational Perspective. In PACIS (p. 137).

[29] Molla, A., and Abareshi, A. (2012). Organizational green motivations for information technology: empirical study. The Journal of Computer Information Systems, 52(3), 92.

[30] Murugesan, S. 2008. Harnessing green IT: Principles and practices. IT professional, 10(1), 24-33.

[31] Malasowe Bridget O., Awodele Oludele and Onuiri Ernest E. (2012). Greening the campus:Desig of a Generic green IT model for possible adoption. (A case study of an educational institution in Nigeria). Asian Journal of Computer Science and Information Technology Journal

[32] Nunn, S. 2007. Green IT: Beyond the data centre how IT can contribute to the environmental agenda across and beyond the business. Accenture, USA.
[33] Rasmussen, N. 2006. Implementing energy efficient data centers.

[34] Rahim, A., Eladwiah, R., and Abdul Rahman, A. (2013). Resource-based Framework of Green IT Capability Toward Firms' Competitive Advantage. Resource, 6, 18-2013.

[35] Schmidt, N.-H., Erek, K., Kolbe, L. M., and Zarnekow, R. 2010. "Predictors of Green It Adoption: Implications from an Empirical Investigation," American Conference on Information Systems p. 367.

[36] SMART 2020 (2008). Smart 2020: enabling the low carbon economy in the information age http://www.smart2020.org/_assets/files/02_Smart2020Report .pdf

[37] Loeser, F. 2013. "Green It and Green Is: Definition of Constructs and Overview of Current Practices," American Conference on Information Systems

[38] Loeser, F., Erek, K., Schmidt, N.-H., Zarnekow, R., and Kolbe, L. M. 2011. "Aligning Green It with Environmental Strategies: Development of a Conceptual Framework That Leverages Sustainability and Firm Competitiveness," American Conference on Information Systems

[39] Liedtka, J. 1991. Organizational value contention and managerial mindsets. Journal of Business Ethics,

10(7), 543-557.

[40] O'Neill, M. 2010. Green It for Sustainable Business Practice: An Iseb Foundation Guide. BCS, The Chartered Institute.

[41] Baregheh, A., Rowley, J., and Sambrook, S. 2009. "Towards a Multidisciplinary Definition of Innovation," Management decision

[42] Herzog, C., Lefevre, L., and Pierson, J.-M. 2012. "Green It for Innovation and Innovation for Green It: The Virtuous Circle," in Ict Critical Infrastructures and Society. Springer, pp. 79-89.

[43] Hasan, H., and Meloche, J. 2013. "Innovative Ict-Mediated Activities for People, Profit and Planet," European Journal of Innovation Management (16:3), pp. 335-354.

[44] Gholami, R., Sulaiman, A. B., Ramayah, T., and Molla, A. (2013). "Senior Managers' Perception on Green Information Systems (Is) Adoption and Environmental Performance: Results from a Field Survey," Information \& Management (50:7), pp. 431-438.

[45] Koomey JG (2007). Estimating Total Power Consumption by Servers in the US and the World. Lawrence Berkeley National Laboratory, Berkeley, CA.

[46] Kumar R (2008). Media Relations. Gartner, Available at: www.gartner.com/it/page.jsp?id $1 / 4781012$.

[47] Lubin, D. A., and Esty, D. C. 2010. "The Sustainability Imperative," Harvard business review (88:5), pp. 42-50.

[48] Tung, L. 2007. Green IT will hit Australian govt'like a ton of bricks.

[49] Viaro, T., Vaccaro, G., Azevedo, D., Brito, A., Tondolo, V., and Bittencourt, C. 2010. 2P. A conceptual framework to develop Green IT-going beyond the idea of environmental sustainability. (47:8), pp. 1323-1339.

[50] McCABE, L. (2010). What is Green IT and why should you care, $7(15)$

$\mathrm{http} / /$ www.smallbusinesscomputing.com/testdrive/article.ph $\mathrm{p} /$

[51] Koo, C., \& Chung, N. (2014). Examining the ecotechnological knowledge of smartgreen IT adoption behavior: A self-determination perspective. Technological Forecasting \& Social Change, 88, 140-155.

[52] Srikanth Subburaj and Siddhivinayak Kulkarni (2014). Analysis of Green IT Features for Improving Business Performance. International Journal for Infonomics (IJI), Volume 7, Issues 1/2, VIC-3353, Asutralia 